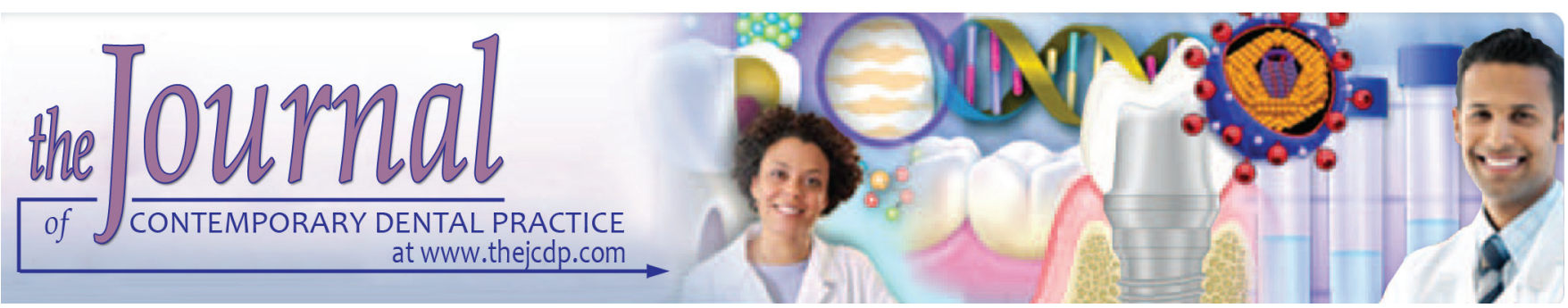

\title{
Assessment of Fracture Resistance Capacity of Different Core Materials with Porcelain Fused to Metal Crown: An in vitro Study
}

${ }^{1}$ Rajesh Vyas, ${ }^{2}$ uchitra, ${ }^{3}$ Prafulla T Gaikwad, ${ }^{4}$ Vishwanath Gurumurthy, ${ }^{5}$ Suraj Arora, ${ }^{6}$ Shashit Shetty

\begin{abstract}
Aim: The aim of the study was to evaluate the capacity to resist fracture in different core buildup materials with porcelain fused to metal (PFM) crown.

Materials and methods: Totally, 45 mandibular single rooted first premolars were collected, which were sound along with similar shape and size. The teeth were sectioned at $15 \mathrm{~mm}$ above the root apex sparing the sound tooth structure. The teeth were endodontically treated with the crown-down technique using nickel-titanium ( $\mathrm{NiTi}$ ) instrumentation. The specimens were randomized into three groups as per the core materials used and were labeled accordingly. Group I consisted of dualcured composite resin, group II consisted of glass ionomer reinforced with resin, and group III consisted of Miracle mix. Universal loading machine is used for measuring the compressive load applied to fracture the tooth.
\end{abstract}

Results: The mean value of compressive strength was maximum in the dual cured composite resin (598.42 \pm 22.64 ) followed by glass ionomer reinforced with resin (478.88 \pm $26.74)$ and Miracle mix $(442.16 \pm 30.10)$. The results showed a significant difference statistically within the core materials used with $p<0.05$. The results from the Tukey's post hoc test

\footnotetext{
${ }^{1,4}$ Department of Dental Technology, College of Applied Medical Sciences, King Khalid University, Abha, Kingdom of Saudi Arabia

${ }^{2}$ Department of Prosthodontics, Bangalore Institute of Dental Sciences, Bengaluru, Karnataka, India

${ }^{3}$ Department of Oral and Maxillofacial Surgery, Datta Meghe Institute of Medical Sciences, Wardha, Maharashtra, India

${ }^{5}$ Department of Restorative Dentistry, College of Dentistry, Abha Kingdom of Saudi Arabia

${ }^{6}$ Department of Restorative Dental Sciences, King Khalid University, Abha, Kingdom of Saudi Arabia

Corresponding Author: Rajesh Vyas, Department of Dental Technology, College of Applied Medical Sciences, King Khalid University, Abha, Kingdom of Saudi Arabia, e-mail: rajeshvyas66@gmail.com
}

of multiple comparisons between dual-cured composite resin vs glass ionomer reinforced with resin, dual-cured composite resin vs Miracle mix, and glass ionomer reinforced with resin vs Miracle mix showed a highly statistical difference with $p<0.05$, which is significant.

Conclusion: This in vitro study showed that the dual-cured composite resin had maximum resistance to fracture compared with other core buildup materials on teeth which were endodontically treated.

Clinical significance: Restoration of a tooth which is structurally compromised is a tricky job for all the dentists. Restoring it with a proper core buildup material with adequate fracture resistance makes the tooth structure stable. The core material should be able to resist all types of occlusal forces and to distribute it equally within the tooth structure.

Keywords: Core buildup, Crowns, Endodontically treated teeth, Fracture resistance.

How to cite this article: Vyas R, Suchitra SR, Gaikwad PT, Gurumurthy V, Arora S, Shetty S. Assessment of Fracture Resistance Capacity of Different Core Materials with Porcelain Fused to Metal Crown: An in vitro Study. J Contemp Dent Pract 2018;19(4):389-392.

\section{Source of support: Nil}

Conflict of interest: None

\section{INTRODUCTION}

There are varieties of restorative materials to restore endodontically treated tooth, but still, it is a tricky job for the clinicians to select the right one, especially in endodontically treated tooth, which has less resistance for occlusal forces due to loss of extensive tooth structure. ${ }^{1}$ The assessment of the remaining dentin in the coronal structure has to be carefully done before deciding to opt for either post and core or direct core buildup.

The structurally compromised tooth fracture is most commonly seen in people who failed to go for restoration 
with core and crown. Core buildup gives sufficient resistance to the tooth structure. A core buildup makes the tooth functionally stable to withstand the occlusal forces and to distribute it to the remaining tooth structure equally. The success of the core buildup material depends on its property to withstand dislodgement resistance and to resist masticatory forces. Failure of core material, in turn, leads to the failure of crown. ${ }^{2}$

The failure of endodontic treatment is said to be more likely because of the improper restoration of the tooth and not mainly because of endodontic therapy itself as per the general agreement. ${ }^{3}$ Following the proper treatment procedure with respect to restorative and endodontic techniques is important. Therefore, for the endodontic treatment to be successful, final restoration plays a major role in root canal therapy. Lack of this may lead to extraction of tooth. ${ }^{4}$

The core was built using a nonmetallic or metallic restorative material. Initially, silver amalgam was the most commonly used core buildup material. Later, glass ionomer cement (GIC) and other modified ionomers were in use. Recently, improved versions of composites with high strength and GIC are used for core buildup. ${ }^{5,6}$

To investigate and to compare the strength of tooth with different materials for core buildup, an appropriate measurable method used was fracture resistance. The fatigue test method is one of the trustworthy methods to access the core buildup material. The fatigue test replicates the clinical situation with that of physiological cyclic load. ${ }^{2}$ Therefore, in this study, the capacity to resist fracture within different core materials with PFM crowns was evaluated.

\section{MATERIALS AND METHODS}

Totally 45 mandibular single rooted first premolars were collected from the Department of Oral and Maxillofacial Surgery, Jaipur Dental College, Jaipur, Rajasthan, India, which were sound along with similar shape and size. The length of the root was calculated from the apex to cusp tip, along with the highest bulge of mesiodistal and buccolingual dimensions, using a digital caliper. The storage of specimens was done at room temperature in $0.9 \%$ saline solution. Specimens which were endodontically treated previously, with restoration or with root caries, were excluded from the study.

All the specimens were sectioned at $15 \mathrm{~mm}$ above the apex of the root leaving sound tooth structure and were treated endodontically using the crown-down method using rotary NiTi instrumentation. The procedure was completed till ISO 40 apical instrumentation and irrigated with sodium hypochlorite $5.25 \%$ solution. The root canal was prepared with $4 \%$ taper with chemomechanical preparation. Obturation was done using vertical warm compaction method (sealer, AH Plus; Dentsply Intl) with gutta-percha (Dentsply Intl). The gutta-percha cone was heat sealed and compacted by creating a space of $11 \mathrm{~mm}$ for the post and with an apical seal of $4 \mathrm{~mm}$. The specimens were mounted on acrylic resin. The teeth mounted were of $12 \mathrm{~mm}$ length from the tip of the root and $3 \mathrm{~mm}$ of the coronal structure above the resin was kept exposed. All the specimens were randomized into three groups and were labeled accordingly. Group I consisted of teeth with dual-cured composite resin core, group II had glass ionomer with resin-reinforced core, and group III had Miracle mix core.

\section{Group I: Composite Resin Dual Cured}

The cavities were prepared and etched for 20 seconds, gently rinsed, and dried. Applied a thin layer of bonding agent and was light-cured for 20 seconds. Dual cure composite resin (Luxacore by DMG, Dental Avenue India) was added incrementally and light cured.

\section{Group II: Resin-reinforced Glass lonomer}

The cavities were prepared and etched for 20 seconds, gently rinsed, and dried. Applied a thin layer of bonding agent and was light-cured for 20 seconds. Glass ionomer cement reinforced with resin (GC Gold Label light cure GIC) was added incrementally and light cured.

\section{Group III: Miracle Mix}

On mixing pad, Miracle mix cement alloy was dispensed along with its liquid (GC Corporation, Tokyo). The powder was sectioned into two parts; the first part was completely mixed for 15 to 20 seconds with all liquid, and later, the remaining part of the powder was mixed for 20 seconds thoroughly. The mixture was then transferred into the area prepared.

Teeth were distributed as 15 under each group. A wax pattern with a thickness of $0.75 \mathrm{~mm}$ was prepared. The conventional casting technique is used for preparing the cast for base metal alloy. Type I GIC was used to cement the crowns. Using a spatula, the cement was loaded on the inner surface of the crown and was fixed to apply pressure through a firm finger.

\section{Testing Procedure}

The universal loading instrument was used to measure the compressive load which causes tooth fractures. The application of the compressive load was done at an angle of $130^{\circ}$ to the tooth's long axis. On the occlusal surface of the teeth, a small sphere was placed upon which the compressive load was applied along the root's long axis. The fracture loads were noted. 
Statistical analysis was done by means of one-way analysis of variance which was followed by the use of Tukey's post hoc analysis. A confidence interval of $95 \%$ with $p<0.05$ was considered statistically significant.

\section{RESULTS}

Table 1 shows the mean values of compressive strength in various core buildup materials used in this study. The mean compressive strength of dual-cured composite resin (598.42 \pm 22.64$)$ showed maximum strength compared with glass ionomer reinforced with resin $(478.88 \pm 26.74)$ followed by Miracle mix $(442.16 \pm 30.10)$.

The mean values of compressive strength in different core materials were compared as shown in Table 2. Analysis of variance showed that there is a high statistical difference between the materials with p-value 0.0001 $(<0.05)$, which is highly significant.

The Tukey's post hoc analysis of multiple comparisons in different core materials is shown in Table 3. According to the analysis, there was a statistical difference with $\mathrm{p}<0.005$ between dual-cured composite resin vs glass ionomer reinforced with resin, dual-cured composite resin vs Miracle mix, and glass ionomer reinforced with resin vs Miracle mix which is significant.

\section{DISCUSSION}

In this study, to eliminate the tooth dimension as its confounding factor, the teeth specimens of similar dimensions were selected and randomized into three groups. ${ }^{7}$ Statistical differences in the length of the teeth or in the cross-sectional dimensions of the teeth between the individual groups were not significant.

During instrumentation, the rotary NiTi instrument was used to promote more tapering of the root canals and to retain cervical dentin. The removal of cervical dentin during instrumentation weakens the tooth structure which predisposes fracture of the root. A study of Zamin et $\mathrm{l}^{8}$ showed that cervical preparation with the highest taper

Table 1: Mean compressive strength of different core materials

\begin{tabular}{llll}
\hline Groups & Core materials & $n$ & Mean \pm SD \\
\hline I & Composite resin dual cured & 15 & $598.42 \pm 22.64$ \\
II & Resin-reinforced glass ionomer & 15 & $478.88 \pm 26.74$ \\
III & Miracle mix & 15 & $442.16 \pm 30.10$ \\
\hline
\end{tabular}

SD: Standard deviation
(\#70/0.12) is more susceptible to root fracture when compared with that of a tooth whose dint had cervical preparation. This is of high importance, as there is an increased use of rotary instruments with more taper nowadays.

From a material aspect, failure of restoration in teeth which is endodontically treated with post and core depends on many factors, which are: the type of post, cementation, surface treatment, and material used for core. ${ }^{9}$ This study was aimed to check the fracture resistance of different core materials through a fracture-resistance test. Except with the type of core material used, other factors were under control to maintain the same condition.

In this study, the mean value of compressive strength in dual-cured composite resins $(598.42 \pm 22.64)$ was maximum, similar to that of Fraga et $\mathrm{al}^{10}$ study result. Fraga et $\mathrm{al}^{\prime} \mathrm{s}^{10}$ study also showed that in cast post and core, there were numerous nonsalvageable fractures compared with that of metal posts along with the composite core. The core buildups with composite resin were preferred, as the load required to fracture is lower than that of the tooth structure.

The composite resin as a core buildup is more resilient and less stiff than that of the metallic core, in turn, less stress transfer to the tooth structure. Yaman and Thorsteinsson ${ }^{11}$ observed that a stiff core material reduces the apical stress but increases the cervical stress.

In the present study and in the works from other researchers, such as Raygot et $\mathrm{al}^{12}$ and Heydecke et $\mathrm{al}^{13}$ it is shown that emphasis and importance were given mainly to the strength of the restoration, post, and core. According to the literature, the load required to fracture the tooth (post or core) is much higher than that of masticatory forces. The higher load occurs mainly during trauma or blow which, it may fracture the natural tooth structure. Therefore, post and core selection should be done based on the remaining tooth structure, restoration used after the buildup, and the tooth occlusal position.

The present study showed that there was a significantly less compressive strength in glass ionomer reinforced with resin compared with that of the composites

Table 2: Comparison of different core materials for mean compressive strength

\begin{tabular}{lllll}
\hline Groups & Mean \pm SD & f-value & $p$-value & Significance \\
\hline I & $598.42 \pm 22.64$ & 58.164 & 0.0001 & HS \\
II & $478.88 \pm 26.74$ & & & \\
III & $442.16 \pm 30.10$ & & & \\
\hline
\end{tabular}

SD: Standard deviation HS: Highly significant

Table 3: Multiple comparisons of core materials using Tukey's post hoc test

\begin{tabular}{llllll}
\hline & & \multicolumn{2}{c}{$95 \%$ confidence interval } & & \\
\cline { 3 - 5 } Core materials & Compared with & Lower bound & Upper bound & Mean difference & $p$-value \\
\hline Composite resin dual cured & Resin-reinforced glass ionomer & 82.1470 & 33.8740 & 119.54 & 0.0001 \\
& Miracle mix & 105.1214 & 56.4328 & 156.26 & 0.0001 \\
Resin-reinforced glass ionomer & Miracle mix & 52.6577 & 27.2130 & 36.72 & 0.03 \\
\hline
\end{tabular}


and more than that of Miracle mix. Cohen et $\mathrm{al}^{14}$ reported that the fatigue resistance of glass ionomer was less compared with that of the composite, similar to that of the present study result. Bonilla et $\mathrm{al}^{15}$ studied five core buildup materials, and results showed that the resistance to fracture was greater in titanium reinforced to composite resin followed by silver amalgam and GIC. Coltak et $\mathrm{al}^{16}$ studied three core buildup materials' fracture resistance which were supported by the post, and the result showed that fracture resistance was greater in composite resin followed by silver amalgam and GIC which was supported by the post. Shah et $\mathrm{al}^{17}$ studied the fracture resistance of the teeth which are endodontically treated and reinforced with various core buildup materials, and the results showed that GIC had high fracture resistance followed by amalgam and Intermediate Restorative Material.

The present study showed that the fracture resistance of the Miracle mix was less than that of other materials. Upadhyay and Kishore ${ }^{18}$ studied silver amalgam and Miracle mix, and the comparative results showed that the Miracle mix (modified GIC with powder of silver amalgam alloy) was aesthetically poor and its strength was less compared with silver amalgam.

Based on the strength, resin-modified GIC and composite resin were used for core buildup as an alternative to that of Miracle mix. The light cure composite has some disadvantages, such as improper curing due to insufficient curing time and intensity of light or too thick material that is being used. Using bonding agent, an excellent tooth adhesion can be achieved but the long-term stability of the bonding agent is unknown. ${ }^{2}$

There were several challenges associated while testing the human teeth mechanically, which includes teeth which were normal developmentally and were not damaged while extraction, sourcing sound, preparation of tooth without creating mechanical or thermal damage, and effect of storage conditions which were unknown. ${ }^{19}$ The in vitro laboratory has its limitations, such as to replicate the elastic property of periodontal ligaments, clinical environment reproduction including masticatory forces, bone, and other supporting tooth structures.

\section{CONCLUSION}

The in vitro study within its limitation concluded that the dual-cured composite resin had fracture resistance higher than that of other core buildup materials used in teeth which were endodontically treated.

\section{REFERENCES}

1. Yalcin E, Cehreli MC, Canay S. Fracture resistances of cast metal and ceramic Dowel and core restorations: a pilot study. J Prosthodont 2005 Jun;14(2):84-90.

2. Mohamed Ali SA, Manoharan PS, Shekhawat KS, Deb S, Chidambaram S, Konchada J, Venugopal N, Vadivel H.
Influence of full veneer restoration on fracture resistance of three different core materials: an in vitro study. J Clin Diagn Res 2015 Sep;9(9):ZC12-ZC15.

3. Alsamadani KH, Abdaziz-el SM, Gad-el S. Influence of different restorative techniques on the strength of endodontically treated weakened roots. Int J Dent 2012;5:15-20.

4. Rashid Habib S, Qasim Al Rifaiy M, Alkunain J, Alhasan M, Albahrani J. Concepts of restoring endodontically treated teeth among dentists in Saudi Arabia. Saudi J Dent Res 2014 Jan;5(1):15-20.

5. Rasimick BJ, Wan J, Musikant BL, Deutsch AS. A review of failure modes in teeth restored with adhesively luted endodontic dowels. J Prosthodont 2010 Dec;19(8):639-646.

6. Cohen BI, Pagnillo MK, Newman I, Musikant BL, Deutsch AS. Effects of three bonding systems on the torsional resistance of titanium reinforced composite cores supported by two post designs. J Prosthet Dent 1999 Jun;81(6):678-683.

7. Zandbiglari T, Davids H, Schafer E. Influence of instrument taper on the resistance to fracture of endodontically treated roots. Oral Surg Oral Med Oral Pathol Oral Radiol Endod 2006 Jan;101(1):126-131.

8. Zamin C, Silva Sousa YT, Souza Gabriel AE, Messias DF, Sousa Neto MD. Fracture susceptibility of endodontically treated teeth. Dent Traumatol 2012 Aug;28(4):282-286.

9. Panitiwat P, Salimee P. Effect of different composite core materials on fracture resistance of endodontically treated teeth restored with FRC posts. J Appl Oral Sci 2017 Mar-Apr; 25(2):203-210.

10. Fraga RC, Chaves BT, Mello GSB, Siqueira JF. Fracture resistance of endodontically treated roots after restoration. J Oral Rehabil 1998 Nov;25(11):809-813.

11. Yaman P, Thorsteinsson TS. Effect of core materials on stress distribution of posts. J Prosthet Dent 1992 Sep;68(3):416-420.

12. Raygot CG, Chai J, Jameson L. Fracture resistance and primary failure mode of endodontically treated teeth restored with a carbon fiber reinforced resin post system in vitro. Int J Prosthodont 2001 Mar-Apr;14(2):141-145.

13. Heydecke G, Burtz F, Hussein A, Strub JR. Fracture strength after dynamic loading of endodontically treated teeth restored with different post and core systems. J Prosthet Dent 2002 Apr;87(4):438-445.

14. Cohen BI, Pangnillo MK, Newman I, Musikant BL, Deutsch AS. Cyclic fatigue testing of five endodontic post designs supported by four core materials. J Prosthet Dent 1997 Nov;78(5):458-464.

15. Bonilla ED, Mardirossian G, Caputo AA. Fracture toughness of various core build-up materials. J Prosthodont 2000 Mar;9(1):14-18.

16. Coltak KM, Yanikolu ND, Bayindir F. A comparison of the fracture resistance of core materials using different types of posts. Quintessence Int 2007 Sep;38(8):e511-e516.

17. Shah P, Gugwad SC, Bhat C, Lodaya R. Effect of three different core materials on the fracture resistance of endodontically treated deciduous mandibular second molars; an in vitro study. J Contemp Dent Pract 2012 Jan;13(1):66-70.

18. Upadhyay NP, Kishore G. Glass ionomer cements-the different generations. Trends Biomater Artif Organs 2005 Jan; 18(2):158-165.

19. Nam SH, Chang HS, Min KS, Lee Y, Cho HW, Bae JM. Effect of the number of residual walls on fracture resistances, failure patterns, and photoelasticity of simulated premolars restored with or without fiber-reinforced composite posts. J Endod 2010 Feb;36(2):297-301. 